(C) 2007 IEEE. Personal use of this material is permitted. Permission from IEEE must be obtained for all other uses, in any current or future media, including reprinting/republishing this material for advertising or promotional purposes, creating new collective works, for resale or redistribution to servers or lists, or reuse of any copyrighted component of this work in other works. 


\title{
Control of a Solid Oxide Fuel Cell Power Plant in a Grid-Connected System
}

\author{
Y. H. Li, S. Rajakaruna, Member, IEEE, and S. S. Choi, Member; IEEE
}

\begin{abstract}
The fastest and yet most prudent ways of changing the output power level of a solid oxide fuel cell power plant connected to the ac-grid are explored. The operating state of the fuel cell power plant is examined in term of the concept of feasible operating area of a cell. The utilization factor of the cell stack is maintained constant in steady-state by feeding natural gas to the fuel processor at a rate proportional to the current drawn from the stack. The fluctuations of the utilization factor in the transient state due to a change in operating power level can be constrained to the allowable range by strategically controlling the current drawn by the power conditioning unit. Based on measured variables and dynamic characteristics of the fuel processor, four strategies of controlling current are compared to arrive at the strategy that results in minimum transient time for a given power change. The proposed control schemes are verified through computer simulations.
\end{abstract}

Index Terms-Distributed generation, feasible operating area, fuel cell $(\mathrm{FC})$, power flow control.

\section{INTRODUCTION}

$\mathbb{F}$ UEL CELLS (FC) are modular, high-efficiency, environmentally friendly energy conversion devices that have become a promising option to replace the conventional fossilfuel-based electric power plants [1], [2]. Among the several kinds of FC, the low-temperature proton exchange membrane fuel cell (PEMFC) is the most widely used type and has been commercialized for the portable, vehicular, and residential applications [3]. [4]. Significant research achievements have also been made in the modeling, control, and performance analysis of PEMFC in the recent past [5]-17]. However, due to the lower efficiency and the dependency on pure hydrogen as the fuel input, PEMFC has not been considered for stationary power applications.

Another kind of $\mathrm{FC}$ under active research is the hightemperature solid oxide fuel cell (SOFC). SOFC presents an attractive option for the distributed generation (DG) technology, which generates electricity at or near the load site. Demonstrative SOFC power plants have been reported in [2]. [13], [18]. [19]. The current main challenges to develop this DG technology are to reduce the installation cost, to improve overall efficiency, and to explore the avenues of increasing the durability to more than $40000 \mathrm{~h}$ for stationary power applications.

The feasibility of using FC power plant for stationary power supply has been studied by many researchers [8]-[16]. In order

Manuscript received July 14. 2004: revised March 2, 2005. Paper no. TEC(0) 19)-20)4.

The authors are with the Center for Advanced Power Electronics, School of Electrical and Electronic Engineering, Nanyang Technological University. Singspore 639798 (e-mail: pg01763737@ @intu.edu.ıg: erajakiruna(a ntu.edu.sg: esschoi(antu.edu.sg).

Digital (object ldentifier 10.11(09/TEC.2005.853756 to ensure that the SOFC would operate successfully in a power system, it is necessary to examine, among other issues, its ability to perform load tracking and its impact on power quality. Central to the studies is the need to have a credible analytical model of the SOFC plant. Thus, building a suitable FC dynamic model is one important aspect in the study of SOFC DG system. In [12], Hall and Colclaser provided an analysis concerning the modeling and simulation of an SOFC under transient state. The FC model includes both the electrochemical and thermal aspects of the cell performance. However, fuel input to the cell has been assumed as constant in the model. The model is also not readily amenable for power system analysis. In a later article. Padullés et al. described a simulation model of an SOFC power plant which is intended for a power system analysis package [13]. In their model, the FC operating temperature has been assumed as constant and the drop of FC electromotive force (EMF) due to the ohmic loss has been considered. The paper shows that the electrochemical and thermodynamic process could be approximated by first-order transfer functions. Also based on the results of $[13]$, Zhu and Tomsovic included the fuel processor in their investigation and used the model to study load-tracking ability of SOFC plant [14]. Unfortunately, the authors did not indicate how the SOFC is to be controlled. Sedghisigarchi and Feliachi adapted the dynamic model discussed in [13] and introduced the effects of temperature variations of the cells in their work [15], [16]. However, one of the most important cell performance variables, fuel utilization, has not been examined when they explored the FC dynamic response after the disturbances.

Based on the work in [13] and [14], this paper focuses on the SOFC dynamic behavior under a grid-connected condition. Specifically, operating issues pertaining to the fuel utilization factor and the power factor of the FC plant will be addressed. The role of the power conditioning unit (PCU) in helping to achieve these objectives is investigated. Section II will review the model derived in [13] and from it, the concept of feasible operating area (FOA) of the FC is introduced. In Section III, the control of real and reactive power flow from the SOFC power plant to the grid is examined. Analytical expressions. which relate the power flow to the hydrogen fuel input and the control variables in the PCU, are derived. Section IV describes the possible strategies in tracking the power demand on the FC. The control objectives are to ensure that the SOFC operates within the FOA under both steady and transient states and also to achieve the required power change in minimum time while operating at a constant power factor with the ac grid. The real power control schemes are illustrated and compared through computer simulations in Section V. 


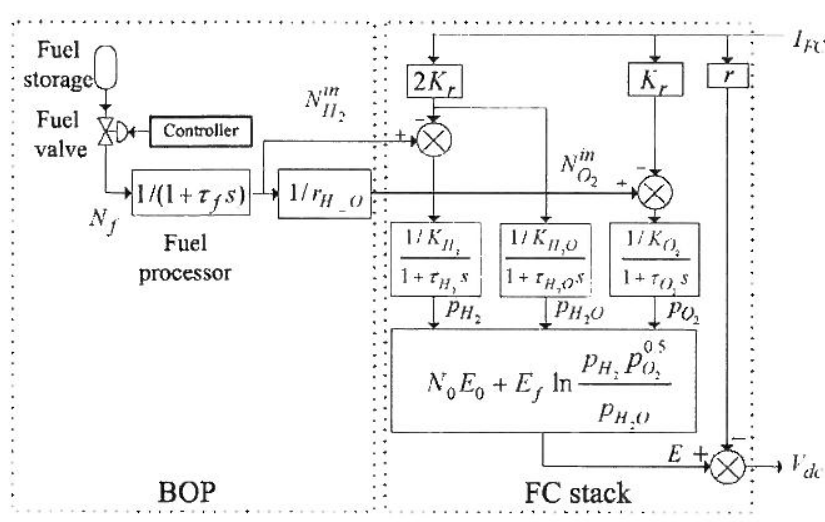

Fig. 1. SOFC dynamic model.

\section{Steady-State Analysis of a SOFC}

\section{A. Bricforervien}

FC converts chemical energy in hydrogen $\left(\mathrm{I}_{2}\right)$ and oxygen $\left(\mathrm{O}_{22}\right)$ directly into electrical energy. The basic reactions at the two electrodes of a SOFC can be described as [17], [18]

$$
\begin{aligned}
& \text { Anode: } \mathrm{H}_{2}+\mathrm{O}=-\mathrm{H}_{2} \mathrm{O}+2 \mathrm{t} \\
& \text { Cathode: } \frac{1}{2}()_{2}+2 t \rightarrow \mathrm{O}^{=} .
\end{aligned}
$$

DC current $\left(I_{\mathrm{F}:(\cdot)}\right)$ in the electrical circuit connected across the two electrodes is generated due to the releasing of the electrons (2c ) at the anode. The well-known Nernst equation is used to calculate the internal EMF generated by the FC stack as

$$
E=N_{0} E_{0}+E_{f} \ln \left(\frac{p_{\mathrm{H}_{2}} p_{\mathrm{O}_{2}}^{(0.5}}{p_{\mathrm{H}_{2}()}}\right)
$$

where $E_{0}$ is the voltage associated with the reaction-free energy of a cell, and $N_{0}$ is the number of stack cells in series. The parameter $E_{f}=N_{0} R T /(2 F)$, where $R$ is the gas constant $(8.31 \mathrm{~J} / \mathrm{mol} \mathrm{K}), T$ is the SOFC operating temperature typically in the range of $800 \mathrm{C}-1000 \mathrm{C}, F$ is the Faraday constant (96487 C/mol), $p_{\mathrm{H}_{2},}, p_{\mathrm{O}_{2}}$, and $p_{\mathrm{H}_{2} \mathrm{O}}$ are the reactant partial pressures of hydrogen, oxygen, and water, respectively.

Based on the work reported in [13] and [14]. a SOFC power plant dynamic model suitable for use in power system studies is shown in Fig. 1. The balance of plant (BOP) consists of the natural gas fuel storage, fuel valve controlled by its controller, and the fuel processor that reforms the natural gas input $N_{f}$ to the hydrogen-rich fuel $N_{\mathrm{II}_{2}}^{\mathrm{in}}$. The fuel processor is represented simply by a first-order lag model of time constant $\tau_{f}$. The natural gas input to the fuel processor $N_{f}$ is controlled according to the current drawn from the FC stack by the feedback controller of the fuel valve, as will be described in Section III.

In the SOFC, the output of the fuel processor is directly fed to the FC stack, which is the second part of the plant shown in Fig. 1. It can be seen from this figure that the hydrogen and oxygen molar flows with the ratio $r_{\mathrm{H}_{-}(}$are sent to the FC stack where the reactions described by (1) occur. In order to allow for oxygen to completely react with hydrogen and maintain the pressure difference between the electrodes below a certain threshold value, excess oxygen $\aleph_{O_{2}}^{m}$ is provided. This means that $r_{H_{-}()}<2$ [14], [17]. The partial pressures of the three reactants are generated as the outputs of three first-order transfer functions where $\kappa_{\mathrm{HI}_{2}}, \mathrm{~L}_{\mathrm{O}_{2}}$, and $\mathrm{K}_{\mathrm{H}_{2} \mathrm{O}}$ are the valve molar constants and $\tau_{\mathrm{H}_{2}}, \tau_{\mathrm{O}_{2}}$, and $\tau_{\mathrm{H}_{2} \mathrm{O}}$ are the respective temperature-dependant time constants for hydrogen, oxygen, and water, respectively. Typical values of the time-constants are of the order of 3 to $80 \mathrm{~s}$. The production of internal EMF $E$ by $N_{0}$ number of cells in series is represented by the block with the Nernst equation given in (2).

Furthermore, there are three types of losses in the generated EMF, namely, the ohmic loss due to the resistance to the flow of ions and electrons, the activation loss due to sluggish electrode kinetics, and the concentration loss due to the concentration gradient formed at the electrodes [17]. [18]. The activation loss is dominant during very low stack currents and the concentration loss is dominant at very high stack currents. The ohmic loss occurs at all levels of currents. In the model shown in Fig. 1, these losses are represented by the resistance $r$. In order to limit mathematical complexity, a constant resistance is assumed in this paper. If increased accuracy is desired, all three losses can be accounted by a nonlinear resistance $r$, which is a function of the operating current level as in [7] and [15]. As discussed later in Section III-C, the proposed control method however is not influenced significantly by the representation of losses.

To maintain plant efficiency and to avoid breakage of cell material, it is necessary to keep the operating temperature $(T)$ of the FC stack within a limited range around its rated value by the thermal management system of the plant [10]. [17]. Therefore, the paper also assumes that $T$ is constant. This operation with relatively constant temperature also places a lower limit on the FC output power [10].

The stack voltage $V_{\mathrm{clc}}$ is the actual voltage available at the terminals after considering the losses. The current drawn from the stack $I_{\mathrm{FC}}$ acts as a feedback to adjust the partial pressures of the reactants according to the reaction rate.

It is interesting to note that in the study of the PEMFC, a similar model has been used in [7].

\section{B. Feasible Operating Area}

One of the most important operating variables that may affect the performance of $\mathrm{FC}$ is its utilization factor $u$. The utilization factor, which is not shown explicitly in Fig. 1, is defined as

$$
u \equiv\left(N_{\mathrm{H}_{2}}^{\mathrm{in}}-N_{\mathrm{H}_{2}}^{\mathrm{o}}\right) / N_{\mathrm{H}_{2}}^{\mathrm{in}}
$$

where $N_{\mathrm{H}_{2}}^{\mathrm{in}}$ and $N_{\mathrm{H}_{2}}^{O}$ are the input and output flow rates of hydrogen. From [13], it can be shown that $u$ can be expressed in term of $I_{\mathrm{FC}}$ as

$$
u=2 K_{r} I_{\mathrm{Fc}} / N_{\mathrm{H}_{2}}^{\mathrm{in}}
$$

$K_{r}$ is a modeling parameter which has a value of $\lambda_{0} /(4 F)$. The desired range of $u$ is from 0.7 to 0.9 . Overused-fuel condition $(u>0.9)$ could lead to permanent damage to the cells due to fuel starvation whereas underused-fuel situation $(u<0.7)$ results in unexpectedly high cell voltages [13]. The value of $u$ 


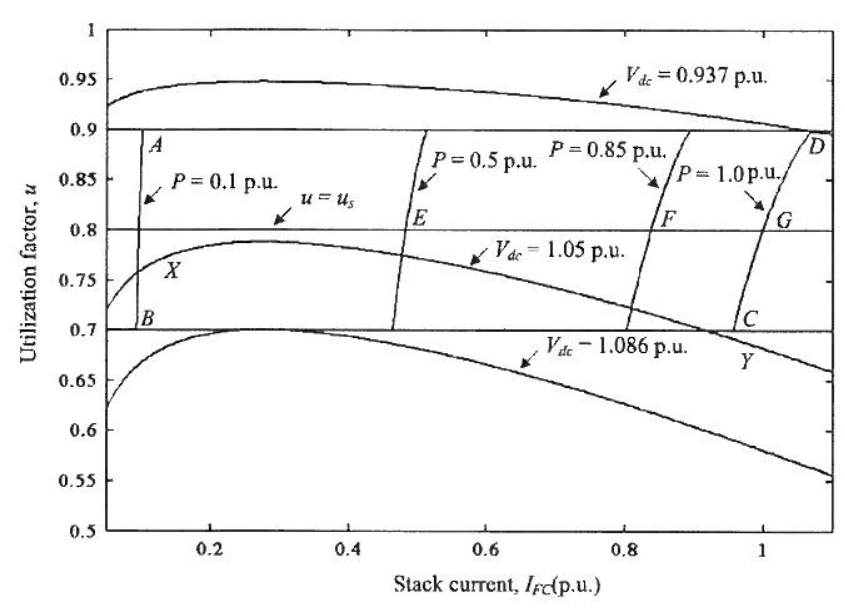

Fig. 2. Feasible operating area of a SOFC.

can be determined online as $N_{I_{1}}^{\mathrm{in}}$ and $I_{\mathrm{Fc}}$ are deemed readily measurable. Hence, it is possible to continuously track the value of $u$. The FC must operate within its rated power and $u$ has to be kept within the allowable range. Under steady state, the relationship between $u, l_{\mathrm{d}}$, and $I_{\mathrm{I}}$ ( can be derived from Fig. 1 as

$$
\left(\frac{1}{u}-1\right)^{2}\left(\frac{2}{u}-r_{\mathrm{H}_{-} \mathrm{O}}\right)=\frac{\exp \left(\tau+2 r I_{\mathrm{F} C} / E_{f}\right)}{J_{\mathrm{F}(}}
$$

where

$i_{i}=2\left(V_{\mathrm{dc}}-N_{0} E_{0}\right) / E_{f}-2 \ln \left[\left(\frac{K_{\mathrm{H}_{2} \mathrm{O}}}{K_{\mathrm{H}_{2}}}\right)\left(\frac{K_{r}}{r_{\mathrm{H}_{-} \mathrm{O}} K_{()_{2}}}\right)^{1 / 2}\right]$.

The detailed derivation of this equation is shown in [21].

Based on the typical SOFC data given in [13] and shown here in the Table II. Fig. 2 shows the relationship between $u$ and $I_{\mathrm{F}}$. obtained through the application of (4) for a range of values of $V_{\text {dc }}$. For example, for a constant $V_{\text {dc }}$ of 1.05 p.u., the relationship between $u$ and $I_{\mathrm{F}}$ ( is given by the curve $\mathrm{XY}$ in Fig. 2. The constraints placed on $u$ are represented by the straight boundary lines $\mathrm{AD}$ and $\mathrm{BC}$ corresponding to an allowable range of $0.7-() .9$. The FC output power $P$, which is simply the product $V_{\mathrm{dc}} I_{\mathrm{T} \text { (c }}$, has been assumed to be confined to the range of $0.1-1.0$ p.u. The boundaries of $P$ are shown by the curves $A B$ and $C D$. Taking all these into consideration, the feasible operating area (FOA) of the SOFC must therefore be within the area ABCDA of Fig. 2. Any operating point outside of FOA will reduce the cell life and is deemed unacceptable.

\section{Power Transfer to Grid}

Unless the load supplied by the FC plant is of do type, the power generated by the FC stack invariably has to be converted to an ac form by using a PCU. Recently, there has been an increased interest in the designing of the most suitable PCU for the FC plant [22]-[26]. Some of the topologies use a boost-type $\mathrm{dc} / \mathrm{dc}$ converter in cascade with a conventional voltage source inverter (VSI) to interface the FC with the ac-grid [22], [23]. Some others omit the dc/dc converter by using a specially de-

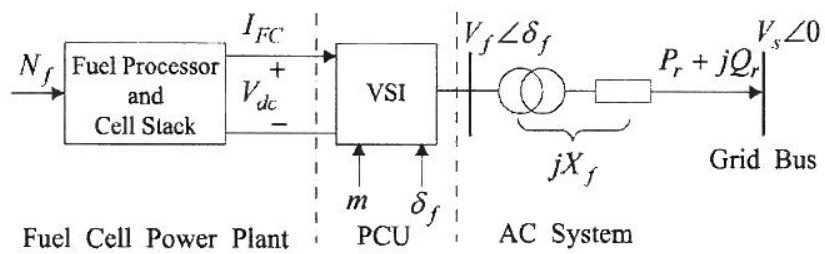

Fig. 3. Schematic diagram of a FC power plant interconnected to an atc-grid.

signed inverter such as the Z-source inverter, which has voltage boosting capability [24]-[26]. In a third category, the conventional VSI is used directly, without the $\mathrm{dc} / \mathrm{dc}$ converter, when the terminal voltage variations of the $\mathrm{FC}$ stack are within the limits that can be handled by the VSI [8], [9]. [15]. As seen from Fig. 2, the operation of the SOFC with a constant utilization factor in steady-state leads to limited terminal voltage variations. Since such variations can be readily handled by the conventional pulsewidth modulated (PWM) VSI through the change of the modulation index, the PCU in this paper consists only of the conventional PWM VSI connected directly to the FC stack terminals. Sinusoidal pulse-width modulation (SPWM) with the two control variables modulation index $(m)$. and the phase shift $\left(\delta_{f}\right)$ is used to control the VSI.

Fig. 3 shows a schematic diagram of the FC power plant interconnected to the external grid. Typically, the output voltage $V_{\text {ic }}$ of the FC stack is relatively low. It is very likely that a step-up transformer would be used to interconnect the VSI to the external grid system. In Fig. 3, the link impedance $X_{f}$ represents the total per-phase series reactance of the transformer and the associated feeder. $X_{f}$ is assumed as a known constant. In order to avoid transformation of variables across the transformer. all the electrical variables used in the following sections of the paper are deemed to be in their per-unit values. It is also envisaged that the power capacity of the FC would be much smaller than the upstream grid system. Therefore, the grid bus could be considered as an ideal stiff source with a magnitude $V_{s}$ at a constant frequency. The measured grid voltage is treated as the reference phasor in controlling the phase shift $\delta_{f}$ of the VSI. The complex three-phase power delivered at the grid bus is denoted as $P_{r}+j Q_{r}$. In the following discussion. only the fundamental components are considered by neglecting the ripples generated due to the switching of the inverter. The ripples can be lowered to desired levels by filtering on both the $\mathrm{dc}$ and ac sides and by increasing the switching frequency of the inverter. Furthermore. the ripple does not contribute to the transfer of real power, which is the focus of this paper. The losses in the switching devices. transformer, and the feeder are also considered negligible.

\section{Power Flow Control in the GRID-CONNECTED SYSTEM}

In the DG system under study, there are three variables that can be used to control the generation and transfer of real and reactive powers. These are the input How rate of natural gas $N_{f}$ of the BOP, the modulation index $m$, and phase shift $\bar{\delta}_{f}$ associated with the VSI. 


\section{A. Control of Fuel Input to the Stack}

According to ( $3 b$ ), the operation of the FC stack with a fuel input proportional to the stack current results in a constant utilization factor in the steady state. Furthermore. such a constant utilization factor operation results in very small deviations in the terminal voltage due to changes in stack current. as seen in Fig. 2 and in [13]. Such small voltage changes can easily be handled by the voltage controllability of the VSI to produce a constant voltage on the ac side. if desired. Thus, the FC stack is operated with a constant steady-state utilization factor by controlling the natural gas input to the stack as

$$
N_{f}=\left(2 K_{r} / u_{s}\right) I_{\mathrm{F}} \cdot
$$

where $u_{s}$ is the desired utilization factor in steady state. In this way, the initial and final operating points in Fig. 2 related to a change in the output power are at the intercepts of the corresponding constant power curves at the two power levels with the $u_{\mathrm{s}}$ line. For example, E, F, and G in Fig. 2 are the operating points when the output power are 0.5 p.u.. 0.85 p.u., and 1.0 p.u., respectively, where $u_{s}$ is shown as 0.8 . Furthermore, with the adoption of this fuel input control strategy and in conjunction with the fuel processor dynamics of Fig. 1, the relationship between a small change of stack current $\Delta I_{\mathrm{F} \text { ( }}$ and a small change of hydrogen input $\Delta N_{\mathrm{H}_{2}}^{\mathrm{in}}$ fed to the $\mathrm{FC}$ stack can be derived as

$$
\Delta N_{\mathrm{H}_{2}}^{\mathrm{in}}=\frac{2 K_{r} / u_{s}}{1+\tau_{f} s} \Delta I_{\mathrm{I} \cdot \mathrm{C}}
$$

\section{B. Control of Power Conditioning Unit}

For the SPWM switching method [20], the rated value of rms phase voltage at the output of the inverter can be derived as

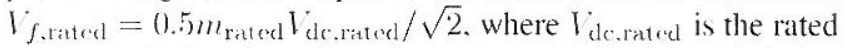
stack terminal voltage in volts and $m_{\text {rated }}$ is the modulation index of the inverter under rated operating condition. Typically $m_{\text {rated }}$ has a value of about 0.8 . By taking $l_{f \text { rated given in }}$ the above equation as the base value, the inverter output phase voltage can be expressed in per-unit form as $V_{f}=m V_{\text {lc. }}$. where $m$ is the per-unit value of the variable modulation index with respect to the base value of $m_{\text {rated }}$ and $V_{\text {ic }}$ is the per unit value of variable stack terminal voltage with respect to the base value of $V_{\text {dc.ratcol }}$. It then follows that the fundamental component of line current $I_{2}$ in p.u. can be expressed in term of its $d-q$ components as

$$
I_{\mathrm{cr}}+j I_{\mathrm{qr}}=\left(I_{f}-\delta_{f}-V_{s}-0\right) / j \mathrm{X}_{f}
$$

where $V_{s}$ is the p.u. voltage at the grid bus. It can be readily shown that the delivered three-phase real and reactive powers at the grid bus in steady state is given by

$$
\begin{aligned}
& P_{r}=V_{s} I_{\mathrm{dlr}}=m V_{\mathrm{dc}} V_{s} \sin \delta_{f} / X_{f} \\
& Q_{r}=V_{s} I_{\mathrm{d} \mathrm{r}}=\left(m V_{\mathrm{dc}} V_{s} \cos \delta_{f}-V_{s}^{2}\right) / X_{f} .
\end{aligned}
$$

Since the power losses in the VSI, transformer, and feeder are neglected, the real power received at the grid bus is equal to the power drawn from the FC stack, i.e., $P_{r^{\circ}}=P=V_{\mathrm{dc}} I_{\mathrm{FC}}$.
Substituting this last equation into (7), it is easily seen that

$$
I_{\mathrm{F} C}=m V_{s} \sin \delta_{f} / X_{f} .
$$

1) Control of PCU for Constant Power Operation: In this system, the reactive power can be generated using the VSI to achieve different operating conditions on the ac side such as constant power-factor, constant voltage, or constant reactive power operation. As the capacity of the DG is considered to be small compared to that of the upstream power system, the constant power factor operation appears to be the likely option in most cases. Under such an operating condition, suppose the SOFC real power output needs to be set to $P_{\text {ref }}$ with a constant power factor angle $y$. From (7)-(9), the two control variables of the VSI would be governed by

$$
\begin{aligned}
\delta_{f} & =\lg _{s}^{1}\left[I_{\mathrm{ref}} /\left(I_{s}^{+2} / X_{f}+P_{\mathrm{ref}} \lg \operatorname{gs}_{\psi}\right)\right] \\
m & =I_{\mathrm{F}}\left(X_{f} /\left(I_{s} \sin \delta_{f}\right) .\right.
\end{aligned}
$$

From (10) and (11), it is seen that the control variable $m$ is dependent on $\delta_{f}$. Furthermore, as the variables on the RHS of the above equations are readily measurable or known, $\delta_{f}$ and $m$ can be determined and applied to the VSI to inject the desired amount of real power to the grid bus and at the desired power factor. Note that due to a transient in the hydrogen input to the FC stack, the values of $V_{\mathrm{d} c}$ and $I_{\mathrm{F} \cdot \mathrm{c}}$ still can change while keeping their product constant.

2) Control of PCU During Power Change's: During a change in the operating power level of the FC, the utilization factor will deviate from its steady-state value $u_{s}$ even when its fuel input is controlled as described in Section III-A. This is because of the delay associated with the fuel processor operation. Therefore, it is necessary to make sure that $u$ is within the allowable range during the transient state as well. This can be accomplished by controlling the VSI to draw a current from the stack to follow a set reference current $I_{\mathrm{F} \text { c r r f }}$. The manner in which $I_{\mathrm{I}: \mathrm{C}, \mathrm{rnf}}$ is derived will be discussed in Section IV. Since the transient periods of a SOFC power plant are much larger than the electrical time constants on the ac side, the steady-state power transfer equations derived as (7) and (8) can still be used during the changes of power level without any significant loss of accuracy. By replacing $P_{\mathrm{ref}}$ in (10) and (11) with $V_{\mathrm{dc}} J_{\mathrm{Fc} \text {.ref }}$, the VSI is controlled during a power change as

$$
\begin{aligned}
& \delta_{f}=\operatorname{tg}^{-1}\left[V_{\mathrm{dc}} I_{\mathrm{FC}, \mathrm{rcf}} /\left(V_{s}^{2} / X_{f}+V_{\mathrm{dc}} I_{\mathrm{FC}, \operatorname{ref}} \operatorname{tg} \varphi\right)\right] \\
& m=I_{\mathrm{F}(\mathrm{rec}} X_{f} /\left(V_{s} \sin \delta_{f}\right)
\end{aligned}
$$

$I_{\mathrm{FC}, \mathrm{ref}}$ will be continuously adjusted until the FC reaches the desired power $P_{\text {rer }}$. Once $I_{\text {rer }}^{\prime}$ has been reached, the PCU is controlled as described earlier for constant power operation. However, due to the action of the fuel controller. $u$ will then recover to its steady-state values $u_{s}$. During this period, both $V_{\text {cle }}$ and $I_{\text {lic }}$ would undergo further adjustments.

\section{Oierall Control Scheme}

Based on the control criteria of the three control variables described in the two preceding sections, the overall control block diagram of the power plant can be depicted as in Fig. 4. In 


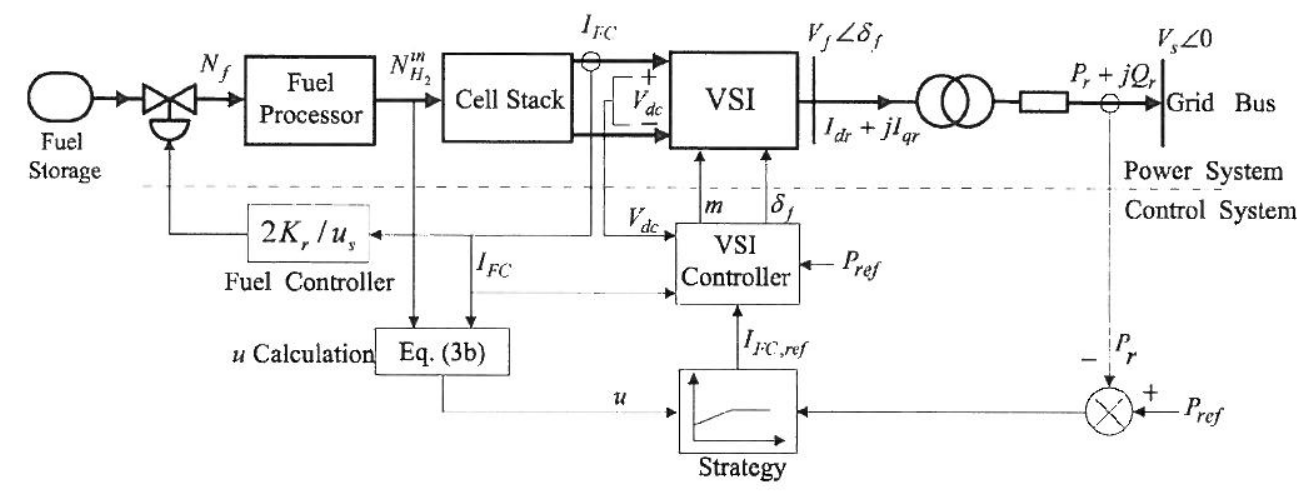

Fig. 4. Block diagram depicting the proposed SoFC control scheme.

the figure, the SOFC power system and its control system are delineated into two distinct parts. The components which constitute the SOFC power system are as described in Section II. The control system consists of the following.

Fucl Controller: The fuel valve is tuned according to the feedback stack current with the proportional gain $2 h_{r} / u_{s}$, as described by (5).

u Calculation Block: From the online measurement of $\mathrm{N}_{\mathrm{H}_{2}}^{\cdot i_{1}}$ and $I_{\mathrm{F}} \mathrm{c} \cdot u$ can be determined from $(3 \mathrm{~b})$ in real time.

Strategy Block: According to the on-line $u$ and power error information, the stack current reference signal $I_{\mathrm{Fc} \text {, ref }}$ is generated. $I_{\mathrm{F} \text { ( }, \mathrm{ref}}$ should be adjusted in a manner as will be described in Section IV.

1SIController: The transient period due to a change in output power can be divided into two distinct parts. During the initial stage, the output power level is forced to reach the desired value $P_{\text {ref }}$ so that the utilization factor is constrained to the allowable range. During this stage, (12) and (13) are used together with the $I_{\mathrm{F}^{*} \mathrm{C} \text {, ref }}$ generated from the Strategy block to determine the appropriate values of $\delta_{f}$ and $m$. The second stage begins when the output power level reaches the desired level $I_{\text {ref }}^{\prime}$. The control equations are changed to $(10)$ and (11) to tune the VSI so that it maintains the real power output at $P_{\text {ref }}$ at a constant power factor for the subsequent periods. With the onset of this stage, the utilization factor begins to recover from its transient value and finally achieves the steady state value $u_{s}$.

Note that the control scheme depends only on the online terminal information of the FC stack. It does not require the knowledge of the internal state of the stack. Hence, any possible loss of accuracy such as in ignoring the activation and concentration losses and in the variations of stack temperature will not affect significantly the effectiveness of the proposed control scheme.

\section{Strategies of Generating Reference Current}

The strategy block is the most important part in the proposed control scheme. A proper $I_{\mathrm{F} \text { ( . . r f }}$ will not only achieve the power demand in minimum time but also guarantee that all the FC transient operating points stay within the FOA. The different strategies of generating the reference current signal are explored below.
From (3b), the small-signal relationship between $\Delta u . \Delta I_{\mathrm{F} \cdot \mathrm{c}}$. and $\Delta N_{H_{2}}^{\text {in }}$ about their initial steady-state values $u_{s} . I_{1:(; 0) \text {, and }}$ $\wedge_{1_{20}}^{\mathrm{in}}$ can be written as

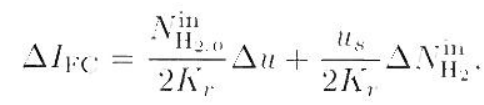

Under constant $u$ control, substituting (6) into (14), and (14) can be rewritten as

$$
\Delta u=\frac{u_{s}}{I_{\mathrm{I}:(\cdot, 0)}} \frac{\tau_{f} s}{1+\tau_{f s} s} \Delta I_{\mathrm{I}:(\cdot}
$$

where $I_{\mathrm{F}(0,0)}$, the initial stack current, is related to the initial $\Lambda_{\mathrm{H}_{2}, 1}^{\mathrm{in}}$ through (5). By denoting $\Delta I=\Delta I_{\mathrm{F}(\mathrm{C}} / I_{\mathrm{F}: \mathrm{C}, 0}$

$$
\Delta u=u_{s} \frac{\tau_{f} s}{1+\tau_{f} s} \Delta l .
$$

It is seen from (16) that the dynamics of $\Delta u$ is a function of the initial stack current, fuel processor time constant and the way how $I_{\mathrm{FC}}$ is manipulated to cater for the real power demand variation. Whichever manner $I_{\mathrm{F}}$ is manipulated, u should not be greater than the maximum allowable value $u_{\max }$. corresponding to the boundary $\mathrm{AD}$ in Fig. 2 or less than the minimum allowable value $u_{\text {min }}$, corresponding to the line $\mathrm{BC}$ in Fig. 2. The possible strategies to generate the reference current signal are as follows.

1) Stcp Change in $I_{\mathrm{F} \text { ( , r f }}$ : If the desired power change $(\Delta P)$ is to be achieved as a step change in current, with the magnitude of the step expressed in term of the initial steady-

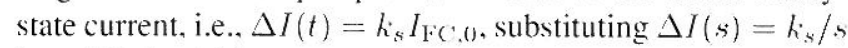
into (16), it yields

$$
\Delta u(t)=u_{s} k_{s} \exp \left(-t / \tau_{f}\right) .
$$

It is seen from (17) that $u$ will have a maximum change equal to $u_{s} k_{s}$ initially, then $u$ will decay in an exponential manner and has the same time constant as the fuel processor. By defining a parameter $\Sigma_{u}$ as

$$
\Sigma_{u}= \begin{cases}\left(u_{\text {nax }}-u_{s}\right) / u_{s} . & \text { for positive } I_{\mathrm{F} c} \cdot \text { step } \\ \left(u_{\text {nin }}-u_{s}\right) / u_{s} . & \text { for negative } I_{\mathrm{F} \cdot} \cdot \text { step }\end{cases}
$$

the initial change in $u$ shall have to be constrained such that

$$
k_{s} \leq\left|\varepsilon_{u}\right| \text {. }
$$


Hence, the maximum allowable step change in current as a ratio of the initial stack current $I_{\mathrm{I}:(\cdot, 0}$ is $\left|\varepsilon_{u}\right|$. Considering the typical values $u_{s}=0.8 . u_{\min }=0 . \overline{\mathrm{T}}$, and $u_{\max }=0.9$, from $(18)$ the maximum safe step of current is $12.5 \%$ of $I_{\mathrm{F}:(., 0}$. As the step change in $I_{\mathrm{I} c}$ is constrained, the allowable FC maximum instantaneous real power change is also limited. If the desired

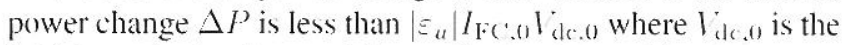
initial terminal voltage of the stack, the demand for the power change $(\Delta P)$ can be achieved instantaneously by a single step. For larger changes of power that cannot be achieved safely by a single step, one of the strategies discussed in the following sections may be applied.

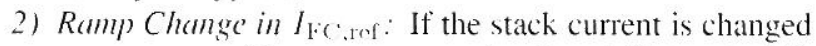
in a ramp manner with a constant rate $k_{r}$, then $\Delta I(s)=k_{r} / s^{2}$. Substituting it into (16)

$$
\Delta u(t)=u_{s} k_{r} \tau_{f}\left(1-\exp \left(-t / \tau_{f}\right)\right) .
$$

It is seen from (20) that $u$ will start from $u_{s}$ and change in an exponential manner. The ramp change is to continue until such time the desired power level $P_{\text {ref }}$ is reached. If the duration of the ramp is much larger than $\tau_{f}$, the final steady state change in $u$ is $u_{s} k_{r} \cdot \tau_{f}$. Since the constraint $u_{\min } \leq u \leq u_{\max }$ has to be satisfied, the limit of the ramp rate $k_{r}$ is given by

$$
k_{r} \leq\left|\varepsilon_{u}\right| / \tau_{f} .
$$

However, if the required power change is smaller, the duration of the ramp can be comparable to the time constant $\tau_{f}$. In such cases, the ramp rate can be increased beyond the limit in (21) and up to a limit calculated using (20). It is also obvious from (20) that with the ramp change in $I_{\mathrm{F}(}, u$ cannot reach either $u_{\text {max }}$ or $u_{\text {min }}$ instantaneously. Hence, it can be concluded that this strategy alone will not produce the effect of reaching the intended power level in minimum time.

3) Simultancous Application of a Step and a Ramp in $I_{\mathrm{F}, \text { ( , ref }}$ : From the discussion of the effects of step and ramp strategies shown in the preceding sections, it can be concluded that the fastest and safe way to achieve a given real power change is to maintain the utilization factor at its maximum allowable value, i.e., $u=u_{\max }$ during a power increase, and at its minimum allowable value, i.e., $u=u_{\min }$ during a power decrease. This means that $\Delta I$ should cause $u$ to experience a step change such that $\Delta u=\varepsilon_{u} u_{s} / \mathrm{s}$. Conversely, the way how $I_{\mathrm{F} \text { ( }}$ should be varied can be obtained by substituting this expression for $\Delta u$ into (16) as

$$
\Delta I=\Sigma_{u}\left(\frac{1}{s}+\frac{1}{\tau_{f} s^{2}}\right) .
$$

To reach the demanded power level in minimum time, (22) shows that $\Delta I$ should consist of a step change with the magnitude $\Sigma_{u}$ superimposed with a ramp change with the fixed ramp rate $\varepsilon_{u} / \tau_{f}$. However, as (22) has been derived on the basis of small-signal linearization. the strategy can be expected to perform well only for small changes of power.

4) Online Control of $I_{\mathrm{FC}, \mathrm{ref}}$ : If the real power demand change $(\Delta P)$ is large, the above three strategies based on the small-signal analysis may no longer be suitable. In order to reach the desired power level $P_{\text {rer }}$ in minimum time, $u$ should

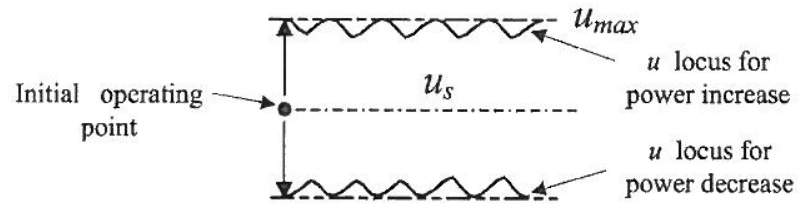

Fig. 5. Expected $u$ loci before the FC reaches the target power.

therefore be instantaneously driven from $u_{s}$ to its appropriate limit value $u_{\text {max }}$ or $u_{\text {min }}$ and maintained at the same value until the desired power level is reached, as depicted in Fig. 5. In this case, reference current $I_{\mathrm{I}^{\circ} \mathrm{C}, \text { r. } \mathrm{f}}$ is not given by a predetermined formula. Instead $I_{\mathrm{F} C \text {, ro }}$ is adjusted online by a feedback control action based on the measured real-time value of $u$. Hence. this control strategy has the added advantages that it not only accommodates power changes of large magnitude but also is independent of the model of the fuel processor.

\section{ILLUSTRATIVE EXAMPLES}

The examples in this section will be used to illustrate how an SOFC power plant in the grid-connected condition can be controlled to change its output power level through the control scheme discussed in Sections III and IV. The example is based on the 10()-kW SOFC plant data given in Table II [13], [14]. The base values used in the examples are $100 \mathrm{~kW}, 330 \mathrm{~V}$ at the FC stack terminals, and $100 \mathrm{~kW}, 400 \mathrm{~V}$ at the grid side of the step-up transformer. The total reactance due to the transformer and feeder is taken as $5 \%$ based on these base values. It is also assumed that it is desirable to operate the SOFC power plant at unity power factor at the system terminal $\left(Q_{r}=(0)\right.$. The controller to the hydrogen fuel is to achieve a constant utilization factor $u_{s}=() . s$. For illustration purposes, $u_{\max }$ and $u_{\text {min }}$ are chosen as 0.9 and 0.7 , respectively. Therefore, $\left|\varepsilon_{u}\right|=0.125$ in this case.

The effectiveness of the design is verified through simulation using the nonlinear model shown in Fig. 1. The simulation tool is MATLAB/SIMULINK. In the following illustrative cases, the power demand is increased to its rated value at $t=30 \mathrm{~s}$ and then is restored back to its original value at $130 \mathrm{~s}$. The purpose is to demonstrate the transient response of the SOFC-grid system during both the increase and decrease of the real power.

\section{A. Simulation Results}

The four strategies discussed in Section IV are used here to achieve different levels of power demand.

Case 1: Step Change in IFC.ref: Pref Changes Between 0.85 and I p.u.: Without limiting the step magnitude. the power change is attempted to be met by a step change in $I_{\mathrm{FC} \text {. . r }}$. Fig. 6 shows the profiles of $u, V_{\mathrm{dc}}, I_{\mathrm{Fc},}$, and $I_{r}$. Although the real power demand can be met instantaneously, it is clearly seen from Fig. 6 that the utilization factor is not constrained to the allowable region during the transient periods. In fact, according to (19). the maximum safe step size is 0.125 of the initial power level. Therefore, power can only have a maximum safe step of ().11 p.u. when the initial power level is 0.85 p.u. 

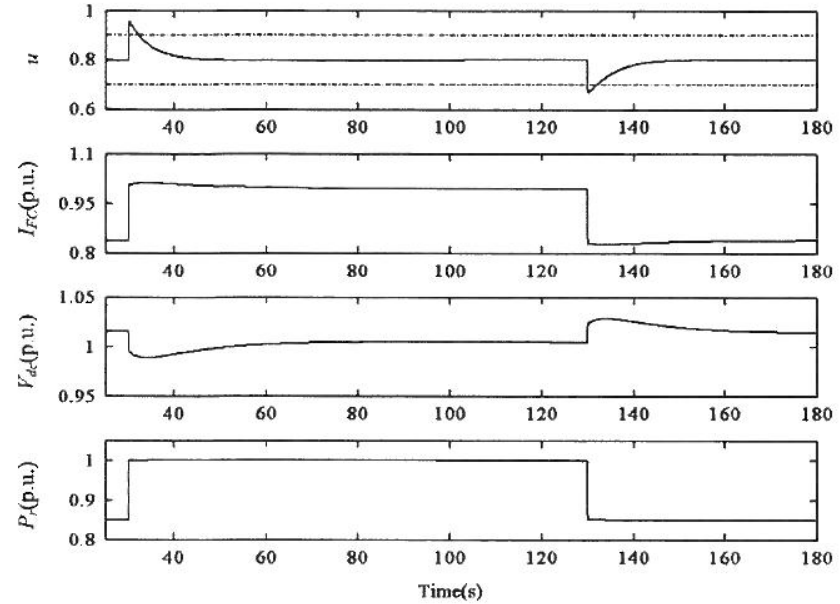

Fig. 6. Power flow control by a vep change in $I_{\text {Fic }}$,ref when $I_{1 \text { ef }}$ changes between $(0.85$ and 1 p.u
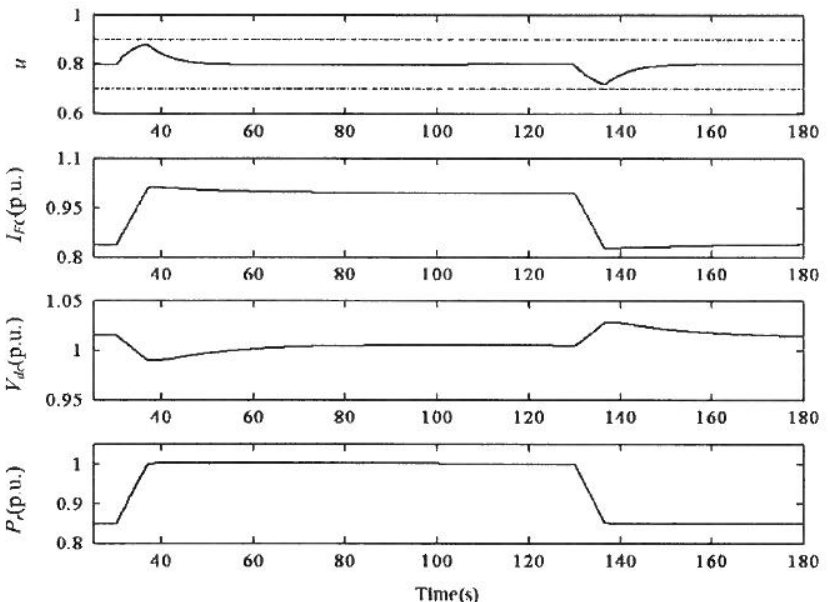

Fig. 7. Power flow control by a ramp change in $I_{\mathrm{FC}}$. wef when $I_{\text {ref }}$ changes between 0.85 and 1 p.u.

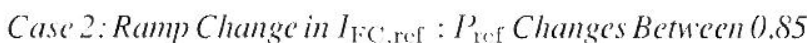
and $I$ p.u.: In order to prevent the SOFC transient operating points from straying outside of the FOA, a ramp change strategy can be attempted with the ramp rate given by (21). Fig. 7 shows the profiles of $u, V_{\mathrm{d} c}, I_{\mathrm{I}, c}$, and $P_{r}$. It is seen that indeed, $u$ remains within the allowable range throughout the transient process. However, due to the small period of ramp resulting from small magnitude of power change, the desired power level is attained even before $u$ reaches its limit. It indicates that it is still possible to reduce the transient time by increasing the ramp rate as determined using (20).

Case 3: Simultaneous Application of a Step and a Ramp in $I_{\mathrm{I}: \text { C.ref }}: P_{\text {ref }}$ Changes Between 0. 85 and $I$ p.u.: To achieve the desired power level in the minimum possible time, the stack current can be increased by application of a step and a ramp, as shown by (22). From Fig. 8 , it is clear that $u$ remains on its limit of $u_{\max }$ or $u_{\min }$ until the FC reaches the target power. As can be seen in the comparison of strategies in Table I, this strategy achieves the target power in a much shorter time compared to the ramp change strategy.
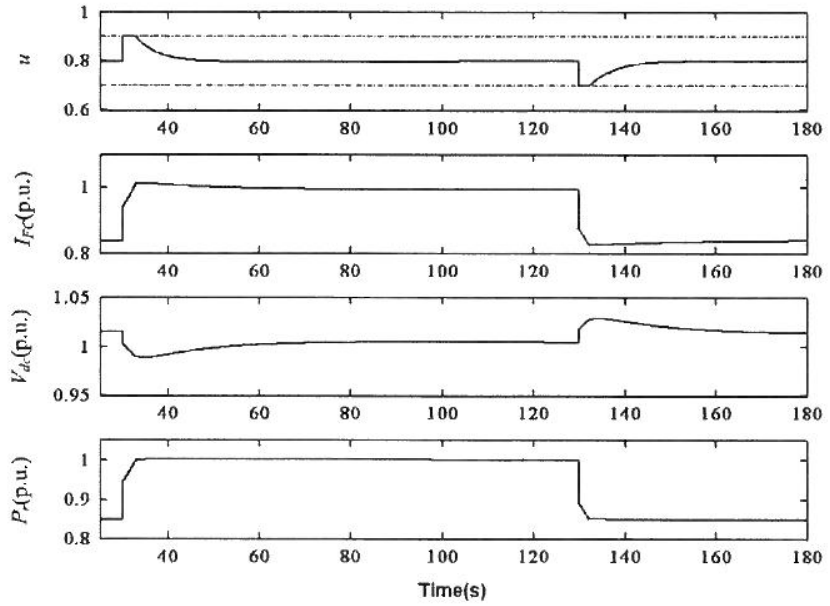

Fig. 8. P'ower flow control by simultaneous step and ramp change in $I_{\mathrm{F}}$ ' reff when $P_{\text {rer }}$ changes between 0.85 and 1 p.u.

TABLE I

COMPARISON OF THI: SIRAII:GIF:S

\begin{tabular}{cccc}
\hline \hline Case & Strategy & $\Delta P(p$ u $)$ & Time(s) \\
\hline 1 & Step & 015 & 0 \\
& & -0.15 & 0 \\
\hline 2 & Ramp & 015 & 6.9 \\
& & -015 & 64 \\
\hline 3 & Step and & 015 & 28 \\
& ramp & -0.15 & 1.7 \\
\hline 4 & Step and & 0.5 & 347 \\
& ramp & -0.5 & 19.1 \\
\hline 5 & On-line & 0.5 & 264 \\
& control & -0.5 & 24.5 \\
\hline \hline
\end{tabular}

Case 4: Simultancous Application of a Step and a Ramp in $I_{\mathrm{F} \text { (c,rer : }}$ Pref Changes Between 0.5 and 1 p.u.: For a power change as large as half of the SOFC rating, the step and ramp strategy given by (22) is applied to reach the target power level. Fig. 9 shows that $u$ can stay at the limit of the allowable region at the initial stage. As time progresses, however, $u$ will deviate from the limit value. In particular, the utilization factor deviates from the allowable range when the real power decreases. This case clearly shows that the simultaneous step and ramp rate strategy can only be applied successfully for a limited range of power changes of the order of $20 \%$. To meet the demand for larger power changes, the $I_{\mathrm{I} \text { ( : I f }}$ must be continuously adjusted.

Case 5: Online Control of $I_{\mathrm{F} C \mathrm{ref}}: P_{\mathrm{ref}}$ Changes Betucen 0.5 and $/$ p.u.: Based on the online calculation of $u$ using the measured hydrogen input and the stack current, $I_{\mathrm{l}: \mathrm{C}, \mathrm{rer}}$ is initially set to drive $u$ to its appropriate limit value $u_{\max }$ or $u_{\min }$ instantaneously. When $u$ starts to deviate from the limit value by more than a set margin, $I_{\mathrm{FC}, \mathrm{ref}}$ is adjusted to force $u$ back to its limit value. Unlike Case 4, the profiles in Fig. 10 show that $u$ stays on its limit value until the FC reaches the target power level. Thus, it is clearly seen that the on-line control of $I_{\mathrm{F}} \mathrm{C}, \mathrm{rof}$ strategy is capable of safely changing the power output of SOFC plant in large proportions and in minimum possible time. 


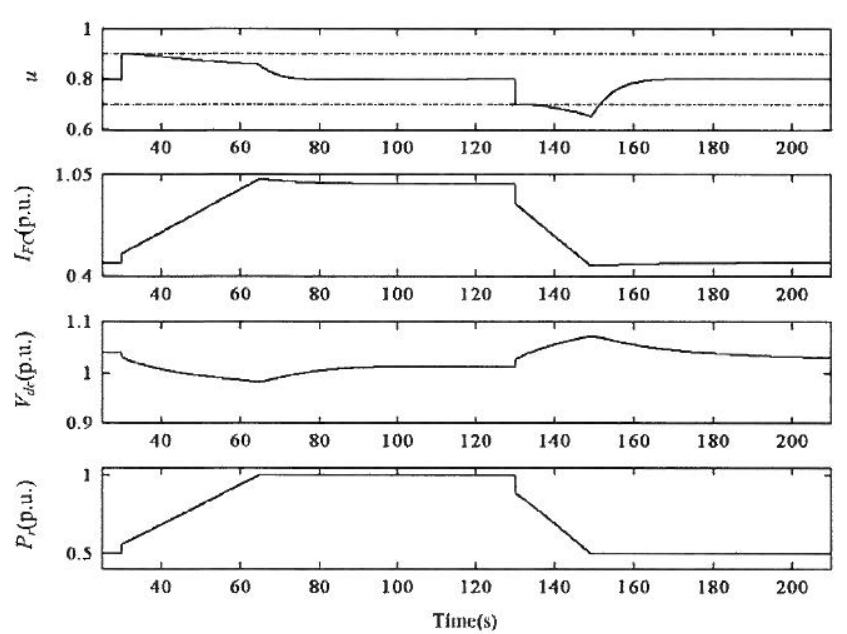

Fig. 9. Power flow control by simultaneous sep and ramp change in $I_{\mathrm{Fc}}$.rof

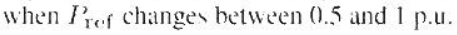
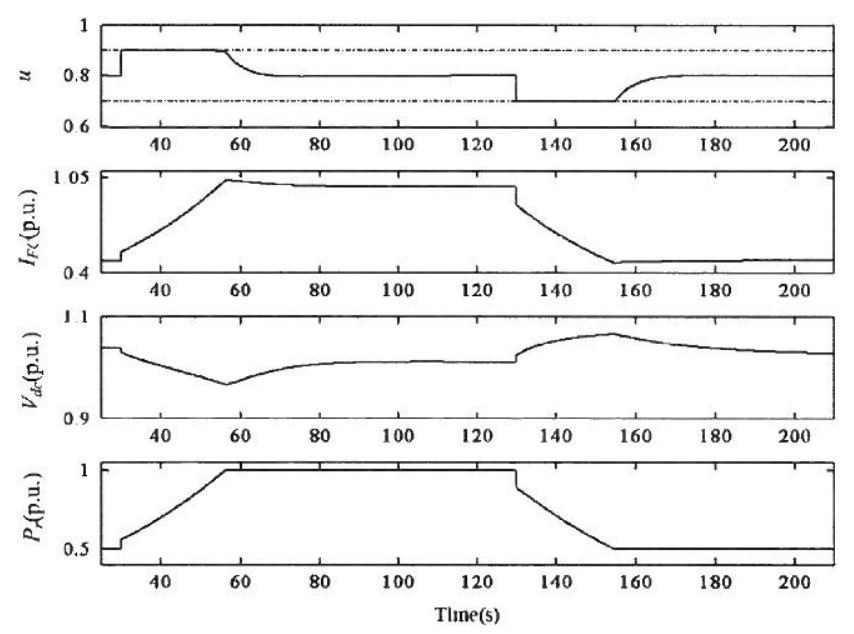

Fig. 10. Power foow control using on-line control of $I_{\text {F c ref }}$ when Prof changer between $(0.5$ and 1 p.u.

\section{B. Comparison of Strategies}

Table I compares the times taken to achieve the different power changes considered in the preceding section.

\section{CONCLUSION}

The strategies of changing the output power level of a SOFC power plant connected to an ac grid through a VSI were explored. The objectives are to minimize the time needed to achieve the power changes while guaranteeing the safe operation of the plant. After identifying the feasible operating area of the FC stack in steady state and considering the power transfer characteristics through a VSI, concepts were formulated to manipulate the three control variables of the power plant. The natural gas input to the plant was controlled proportionally with the current to operate the stack with a constant utilization factor in steady-state and reduced terminal voltage variations. The phase shift and modulation index of the VSI were utilized to regulate the stack current and to keep the power factor of the
TABLE II

PARAVIETIRS IN THE PROTOIYPL: SOFC POWER PIAAI

\begin{tabular}{|c|c|c|}
\hline Symbol & Representation & Value \\
\hline$P_{\text {nated }}$ & $\begin{array}{l}\text { rated power } \\
\text { rated FC terminal voltage }\end{array}$ & $\begin{array}{l}100 \mathrm{~kW} \\
330 \mathrm{~V}\end{array}$ \\
\hline$T$ & operation temperature & $1273 \mathrm{~K}$ \\
\hline$E_{0}$ & ideal standard potential & $1.18 \mathrm{~V}$ \\
\hline$N_{0}$ & number of series cells in the stack & 384 \\
\hline$K_{r}$ & modeling constant & $0.993 \times 10^{-3} \mathrm{~mol} /(\mathrm{s} \mathrm{A})$ \\
\hline$u_{3}$ & fuel utilization factor setting & 0.8 \\
\hline$K_{\mathrm{H}_{2}}$ & hydrogen valve molar constant & $0.843 \mathrm{~mol} /(\mathrm{s} . \mathrm{atm})$ \\
\hline$K_{\mathrm{H}_{2} \mathrm{O}}$ & water valve molar constant & $0.281 \mathrm{~mol} /(\mathrm{s} \mathrm{atm})$ \\
\hline$K_{\mathrm{O}_{2}}$ & oxygen valve molar constant & $252 \mathrm{~mol} /(\mathrm{s} \mathrm{atm})$ \\
\hline$\tau_{B_{2}}$ & hydrogen flow response time & $261 \mathrm{~s}$ \\
\hline$\tau_{\mathrm{H}_{2} \mathrm{O}}$ & water flow response time & $78.3 \mathrm{~s}$ \\
\hline$\tau_{\mathrm{O}_{2}}$ & oxygen flow response time & $2.91 \mathrm{~s}$ \\
\hline$\tau_{j}$ & fuel processor response time & $5 s$ \\
\hline$r$ & ohmic loss & $0.126 \Omega$ \\
\hline$r_{H_{-} O}$ & ratio of hydrogen and oxygen & 1.145 \\
\hline
\end{tabular}

plant constant for all power levels. Different manners in which the stack current can be changed were studied to achieve the objectives. Through the analysis, it was found that the maximum safe step in stack current as a ratio to the initial stack operating current is equal to the maximum allowed excursion of the utilization factor. as a ratio to the steady-state utilization factor. For larger power ranges, the stack current should be varied using a feedback control loop so that the utilization factor is maintained at its limit value until the target power level is achieved. For this method of control, the controller is independent of the model of the fuel processor. Furthermore, with all the strategies of current control, the controller is independent of the model of the FC. Computer simulations have verified the accuracy of the theoretical analyses and predictions.

\section{REFERENCES}

[1] M. W. Ellis, M. R. Von Spakorsky, and D. J. Nelson, "Fuel cell sysems: Efficient, flexible energy conversion for the 21 st century," Proc IEEE. vol. 89, no. 12, pp. 1808-1818, Dec. 2001.

[2] M. Farooque and H. C. Maru, "Fuel cells-the clean and efficient power genarators," Proc IEEL, vol. 89, no. 12. pp. 1819-1829. Dec. 2001.

[3] H. Oman, "Electric car progres," HEEE Acrosp. Electron. Syst. Mas. vol. 17, no. 6, pp. 3()-35. Jun. 20()2.

[4] L. P. Jarvis, P. J. Cygan, and M. P. Roberts, "Hybrid power source lor manportable applications," IEEE Aerosp. Electron. Syst. Mag., vol. 18. no. 1. pp. 13-16, Jan. 2003.

[5] L. Y. Chiu, B. Diong. and R. S. Gemmen, "An improved small-signal model of the dynamic behavior of PEM fuel cells." HEEE Trans. Ind. App/.. vol. 40, no. 4. pp. 97()-977, Jul./Aug. 2(1)4.

[6] W. Friede, S. Ratel, and B. Davat, "Mathematical model and characterization of the transient hehavior of a PEM fuel cell," IEEE Trans. Porter Electrom., vol. 19, no. 5, pp. 12.34-1241, Sep. 20(14.

[7] M. Y. EI-Sharkh ot al.. "Analysis of active and reactive power control of a stand-alone PEM fuel cell power plant," IEEE Trans. Porrer Syst.. vol. 19. no. 4, pp. 2022-2028, Nov. 2004.

[8] R. Kyoungsoo and S. Rahman. "Two-loop controller for maximizing performance of a grid-comnected photowoltaic-fuel cell hybrid power plant," IEEE: Trans. Energy Comers., vol. 13, no. 3, pp. 276-281, Sep. 1998.

[9] C. J. Hatziadoniu. A. A. Lobo, and F. Pourboghrat, "A simplified dynamic model of grid-comnected fuel cell generators," IEEE: Trans. Power Del. vol. 17. no. 2. pp. 467-473, Apr. 2002. 
[10] S. Krumdieck. S. Page, and S. Round, "Solid oxide luel cell architecture and yysem design for secure power on an unstable grid." I Poner Sonmecs. vol. 125, no. 1, pp. 189-198. Jan. 2(104

[11] IEEE Standard (drafi) for Distributed Resentres Interomnected With Electric Pencer Sistems. Jun. 20(03. IEEE P1547.

[12] D. J. Hall and R. G. Colclaser. "Transient modeling and simulation of a labular solid oxide fucl cell," H:FE: Trans. Encrey Comers. 1ol. 14, no. 3. pp. 749-752. Dec 1999.

[13] J. Padulles. G. W. Ault, and J. R. McDonald, "An integrated SOFC plant dynamic model for power ystems simulation," I Pence Sontecs. 101.86. no. 1-2. pp. 495-50)( Mar. 2000.

114] Y. Khu and K. Tomovic. "Development of modek lor analyzing the loadfollowing performance of micro-turbines and fuel cells.".J. Electric Power Sist. Res., vol, 62, no, 1, pp. 1-11. May 20)(12.

$[15]$ K. Sedghisigarchi and A. Feliachi. "Dynamic and transient antalysis of poucr distribution systems with fuel cells-Part I: Fuel-cell dynamic model," HEFE Trans Encres (omers.. vol. 19, no. 2. pp. 423-428, Jun. $20(14$.

[16] - "Dynamic and transient analysis of power distribution w stems with fuel cells-Part II: Control and sability enlancement," ILEE Trums. En(c) Comers, vol. 19, no. 2, pp, 429-4,34, Jun. 20014.

[17] L. J. Blomen and M. N. Mugerwa, Finel Cell Sistems. New York. Wiley: 1993.

[18] J. Larminie and A. Dicks, Fuc/ Coll Sistem Lyplained. 2nd ed. New York, Wiley, $20(1) 2$.

[19] Finel Coll Tordmology Handhesh. Bocat Ratom, FL: CRC, $20(12$.

[20] N. Mohan. T. M. Undeland, and W. P. Rohbins, Poncr Elcetronics: Converters. Applications, and Design, 3rded. New York, Wiley, 2003.

[21] Y. H. Li. S. S. Choi, and S. Rajakarunal, "An analysis of the control and operation of a volid oxide fuel cell power plant in an isolated ystem," IEEE Trums. Energy (omers., vol. 20, no. 2, pp. 381-387. Jun. 2005.

[22] S. K. Mazumder ot al.. "Solid-oxide-fuel-cell performance and durability: Resolution of the effects of power-conditioning systems and application

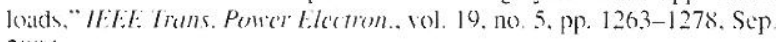
2()$(04$.

[23] J. Wang e't al., "Low cos fuel cell comerter sysem for residential power generation," HEFE: Tiums. Pourer Eilectron., vol. 19, no. 5. pp. 1315-1322, Sep. 2004

[24] F. Z. Peng, "7.source inverter," IE:F: Trans. Ind. Appl., wol. 39, 130. 2. pp. $5(14-510$, Mar. 2003 .

[25] F. Blatabjerg. 7. Chen, and S. B. Kjater, "Power electronice an efticient interface in dispersed power generation systems." IF:LE: Trans. Ponce Electron. vol. 19, no. 5, pp. 1184-1194. Sep. 2004.

[26] C. Cecatti, A. D. Aquila, and M. Liserre, "A novel three-phase single-stage distributed power inverter." IEEE: Tians, Power Electron., vol. 19. no. 5 , pp. 1226-1233, Sep. 2004
Y. H. Li received the B.E. and M.Eng, degree from Huathong (Inicersily of Science and Technology: Wuhan, China, in 1994 and 1998, respectively. $\mathrm{He}$ is working loward the Ph.D. degree at Nanyang Technological University Singapore.

He was a Lecturer Wuhan University, Wuhan, China, from 1998 to 2001 . He joined Nanyang Technological Universily in 20()1.

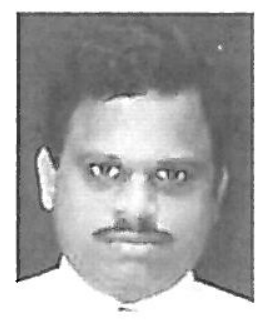

S. Rajakaruna $\left(M^{\prime} 9,3\right)$ received the B.Sc.Eng. degree from the University of Moraluwa, Moratuu at. Sri Lanka, in 1989, the M.Sc. degree from the Univerity of Calgary, Calgary. AB. Canada, in 1989. and the Ph.D. degree from the Universily of Toronto. Toronto. ON, Canada, in 1993.

In 1986, he joined the Department of Electrical Engineering. University of Moratuwal an an Assistant Lecturer. Upon the completion of port-graduate studies, he served the same department as at Senior Lecturer from 1993 to 1999 . After a period of one year at the Department of Electrical Engineering. University of Toronte, at : Visiting Professor, he joined the Power Engineering Division. Nanyang Technological University, Singapore. in October 2000 , where he is currently working as an Asistant Professor. His current research interess include distributed generation. new energy storage techniques, and induction generators

Dr. Rajakaruna is a member of The Institution of Electrical Engineers (IEE) and at Chartered Engineer.

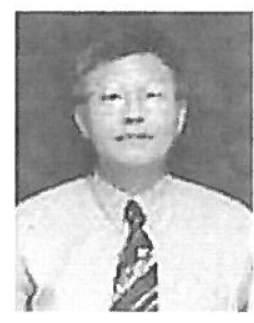

S. S. Choi (M76) received the B.E. and Ph.D. degrees from the University of Canterbury. Christchurch, New 7ealand, in 1973 and 1976. respectively.

He then worked in the New \%ealand Electricity Department before he took up a lecturing poss at the National Universty of Singapore in 1978. He joined the State Energy Commision of Western Australia (SECWA) in 1981, where he was responsible for sytem sudies pertaining to stabilities, voltage control. power quality, SVC application, and network transients. From 1989 to 1992, he was Head of the System Analysis Section. Ho left SECWA in Oetober 1942 10 join the School of Electrical and Electronic Engineering, Nanyang Technological University. Singapore, where he is now a Professor. His research interests are power system dynamics, FACTS, and power yuality.

Dr. Choi received the IEE S. \% De Ferranti Premium Award for the 19891990 sewion. He is at member of The Institution of Electrical Engineers (IEE) and the Institution of Engineers, Australia. He is a Chartered Professional Engineer of Australiat. 